\title{
Groundwater chemical anomalies connected with the Kamchatka earthquake (M=7.1) on March 1992
}

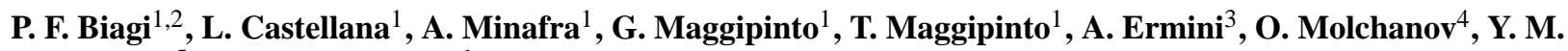 \\ Khatkevich $^{5}$, and E. I. Gordeev ${ }^{6}$ \\ ${ }^{1}$ Department of Physics, University of Bari, Via Amendola, 173, 70126 Bari, Italy \\ ${ }^{2}$ Inter-Department Centre for the Evaluation and Mitigation of the Volcanic and Seismic Risk, University of Bari, Italy \\ ${ }^{3}$ Department of Engineering of Enterprise, University of Roma Tor Vergata, Via di Tor Vergata, 00133 Rome, Italy \\ ${ }^{4}$ United Institute of the Earth's Physics, Russian Academy of Science, Bolshaya Gruzinskaya 10, 123995 Moscow, Russia \\ ${ }^{5}$ Experimental and Methodical Seismological Department, Geophysical Service, Russian Academy of Science, Pijp Av. 9, \\ Petropavlovsk-Kamchatsky 683006, Russia \\ ${ }^{6}$ Institute of Volcanology and Seismology, Russian Academy of Sciences, Pijp Av. 9, Petropavlovsk-Kamchatsky 683006, \\ Russia
}

Received: 26 June 2006 - Revised: 27 September 2006 - Accepted: 27 September 2006 - Published: 4 October 2006

\begin{abstract}
The energy released by the earthquakes occurred in the seismogenetic area of the southern Kamchatka (Russia) from January 1977 to December 2004, reveals an increase in the peak energy in the period 1992-1999. This increase is related to the occurrence of seven earthquakes with magnitude ranging from 6.9 to 7.7; the first of these earthquakes happened on 2 March 1992 with $M=7.1$. For many years, hydro-geochemical data have been collected with a mean sampling rate of three days, in the form of the most common ions and gases in the water of deep wells and natural springs of a network operating in the south area of the Kamchatka, where the capital city Petropavlovsk is located. The collected data were analysed and differences in the trend and in the spectral content of some hydro-geochemical parameters at the springs were pointed out before and after the occurrence of the March 1992 earthquake, indicating clear post-seismic effects. Then an evident increase in the Carbon Dioxide and in the Hydrogen content appeared practically at each measurement site during the two-four years preceding the earthquake, so that long term precursors can be claimed. Finally, an anomalous decrease in the Carbon Dioxide content at the springs was revealed two/three months prior the earthquake, as a middle term precursor. The earthquake on March 1992 was the event nearest $(90-120 \mathrm{~km})$ to the measurement sites that happened in last thirty years.
\end{abstract}

$\overline{\text { Correspondence to: } \mathrm{P} . \mathrm{F}}$. Biagi

(biagi@ fisica.uniba.it)

\section{Introduction}

The southern area of the Kamchatka peninsula, where the capital city Petropavslosk is located, is an active margin where the Pacific plate subducts beneath the Eurasia plate. The majority of the earthquakes occur in a zone located offshore, $60-100 \mathrm{~km}$ far from the Pacific coast of the peninsula (Fig. 1), with focal depths up to $650 \mathrm{~km}$. In this zone, earthquakes with magnitude (M) greater than 8.0 can take place; the strongest one in the last decades $(M=8.5)$ happened on 4 November 1952. Earthquakes also occur in the continental part, but much less frequently than the ones in the previous zone (Fedotov et al., 1985).

The geochemical Team of the Kamchatka Geophysical Service, Russian Academy of Sciences, is measuring since 1977, with a mean sampling rate of three days, the content of the most common ions and gases in water samples collected in a network composed by six deep (500-2500 m) wells and two natural springs located in the Petropavlovsk area, at a maximum distance of $50 \mathrm{~km}$ from the city. In some of the sites, other parameters, as the flow rate and the water temperature, are also sampled. The wells are here labelled $\mathrm{W}_{1}, \mathrm{~W}_{2}$, $\mathrm{W}_{3 \mathrm{a}}, \mathrm{W}_{3 \mathrm{~b}}, \mathrm{~W}_{3 \mathrm{c}}, \mathrm{W}_{4}$ and the springs are $\mathrm{S}_{1}$ and $\mathrm{S}_{2}$. Their locations are indicated in the Fig. 1. Here the wells $\mathrm{W}_{3 \mathrm{a}}, \mathrm{W}_{3 \mathrm{~b}}$, and $\mathrm{W}_{3 \mathrm{c}}$ are indicated as $\mathrm{W}_{3 \mathrm{a}, \mathrm{b}, \mathrm{c}}$ because they are located at distances of some hundred meters from each other; for the same reason, the two springs are marked with $\mathrm{S}_{1,2}$. The $\mathrm{W}_{1}$ well is close to the springs and in Fig. 1 a single mark is used. In the past, different analyses were performed in order to reveal possible correlations between anomalous variations of the hydro-geochemical parameters and the seismic activity

Published by Copernicus GmbH on behalf of the European Geosciences Union. 


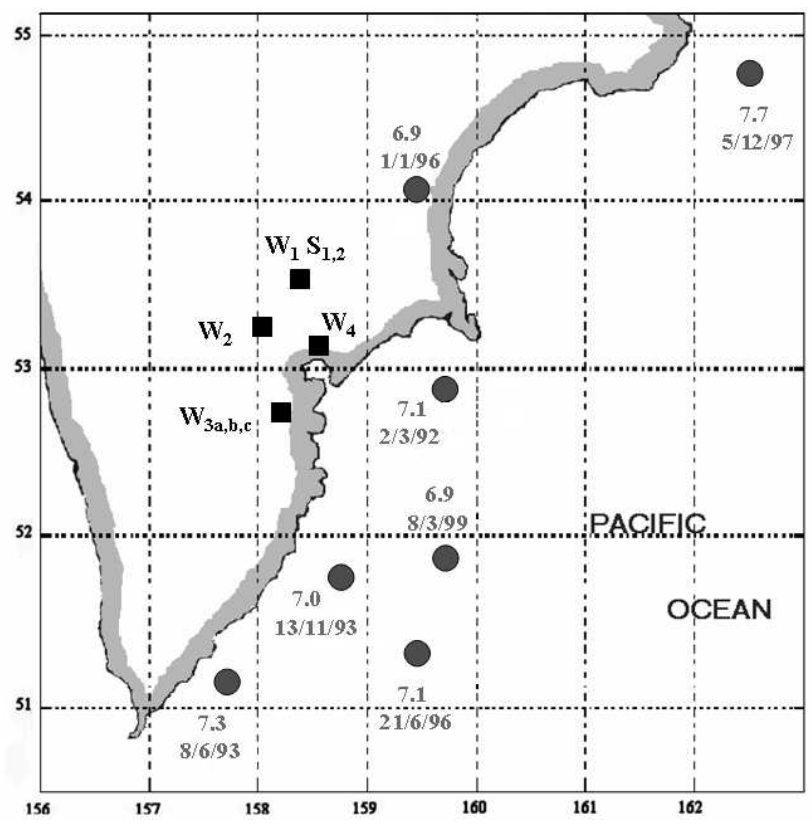

Fig. 1. Map of the southern part of the Kamchatka peninsula. Black squares indicate the location of the six wells and of the two natural springs. The circles show the epicentres of the seven main earthquakes occurred in the zone in the last thirty years. Their time occurrence (day, month, year) and magnitude are indicated, too.

(Bella et al., 1998; Biagi et al., 1999, 2000a, b, 2001a, b, 2003, 2004a, b; Kingsley et al., 1999, 2001). On this subject here we present a further investigation that has pointed out clear groundwater chemical anomalies on the occasion of the March 1992 earthquake (M=7.1).

\section{Data analysis}

In order to analyse the seismic activity of the southern Kamchatka, the seismic catalogue of the Seismological Service of Kamchatka was used. At first, the earthquakes located in a circle of a radius of $350 \mathrm{~km}$ around the centre of the hydro-geochemical network from January 1977 to December 2004, were selected and their $k$ (the logarithm of energy in joule) values were considered. Then, the $k_{s}$ index proposed by Molchanov et al. (2003) and the $\varepsilon$ index proposed by Dobrovolksky et al. (1979) were evaluated. These indices are related to the magnitude and to the location of the earthquakes. The $k, k_{s}$ and $\varepsilon$ trends are reported in Fig. 2 and all the trends show an increase in the peak energy release from 1992 to 1999. This increase is related to the occurrence of seven earthquakes with magnitude around 7.0 and above. This is in contrast with the previous decade when the seismic activity was more moderate and only two large earthquakes occurred with $\mathrm{M}=6.0$ and $\mathrm{M}=6.5$ in 1983 and in1987, respectively. The location, magnitude and time occurrence of the quoted seven earthquakes are indicated in the Fig. 1. The first one (M=7.1) occurred on 2 March 1992 offshore, at distances of $90-120 \mathrm{~km}$ from the measurement sites. It was the largest event that occurred closest to the hydro-geochemical network in the last thirty years.

The raw data trends of $\mathrm{Cl}, \mathrm{Na}, \mathrm{Ca}$ and $\mathrm{HCO}_{3}$ ions content in the water of the spring $S_{2}$ reported in Fig. 3, show clearly different features before and after the March 1992 earthquake occurrence. Moreover, the same effect appears also in both $\mathrm{N}_{2}$ and Ar water contents at the same spring (Figs. 4a and b). In particular, the spectral analysis applied on these data in the years before and after the earthquake, reveals the appearance of a strong component with a period of 6 days in the spectra related to the years after the earthquake occurrence. A different feature, that is the appearance in the spectrum of a strong annual component after the earthquake occurrence, is recognizable also in the trend of the groundwater $\mathrm{CO}_{2}$ content at spring $\mathrm{S}_{1}$ (Fig. 4c).

The $\mathrm{H}_{2}$ and $\mathrm{CO}_{2}$ contents in the water sampled from the springs $S_{1}$ and $S_{2}$ are shown in the Figs. 5a and b. Evident anomalous increases in these contents appear during the twofour years period preceding the 2 March 1992 earthquake. The analysis of the hydro-geochemical data from the wells reveals similar increases. As an example, the Figs. 6a and $\mathrm{b}$ show the increases in $\mathrm{H}_{2}$ and $\mathrm{CO}_{2}$ contents at $\mathrm{W}_{3 \mathrm{~b}}$ and $\mathrm{W}_{2}$. At this last well, anomalous variations with the same duration seem to appear also in the $\mathrm{CH}_{4}$ content and in the water temperature $T$.

Finally, the decreases in the $\mathrm{CO}_{2}$ content at the springs $\mathrm{S}_{1}$ and $S_{2}$, defined by the red arrows in the Figs. $5 \mathrm{a}$ and $\mathrm{b}$ and enlarged in the Fig. 5c, can be considered anomalous variations preceding the March 1992 earthquake with a two/three months duration.

\section{Discussion}

At first, it must be noted that co-seismic effects cannot be revealed by the hydro-geochemical data collected in the network since they are sampled on average each three days. So, among the co-post seismic effects only the post-seismic ones can be revealed. The evident increase in the content of $\mathrm{Cl}$, $\mathrm{Na}, \mathrm{Ca}$ and $\mathrm{HCO}_{3}$ ions shown in the Fig. 3, represent a clear example of such effects. The fractures and cracks due to the earthquake, produced the mixing of $S_{2}$ groundwater with new water characterised by larger salinity, i.e. larger amount of Sodium chloride (from the ionic dissociation of which the $\mathrm{Cl}$ and $\mathrm{Na}$ ions come) and by a larger amount of Calcium carbonate and/or Calcium sulphate (from the ionic dissociation of which the $\mathrm{Ca}$ ion comes). These processes could justify the increase of the $\mathrm{Cl}, \mathrm{Na}$ and $\mathrm{Ca}$ contents. Then, a greater groundwater $\mathrm{pH}$ value could justify the increase of the $\mathrm{HCO}_{3}$ content. In fact this ion comes from the ionic dissociation in water of the carbonic acid $\left(\mathrm{H}_{2} \mathrm{CO}_{3}\right)$ and this dissociation increases with increasing $\mathrm{pH}$ value (Fornaseri, 1994; Mason and Moore, 1982). 

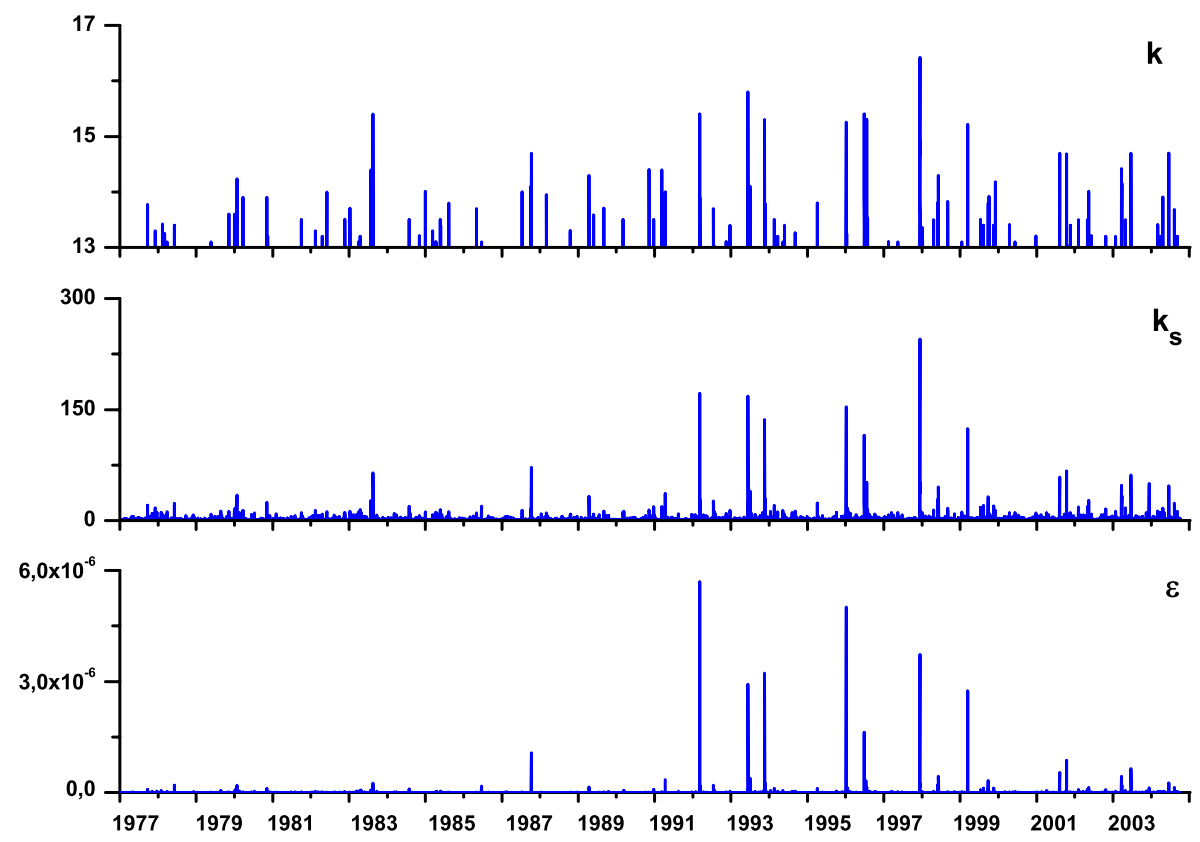

Fig. 2. Energy released by the earthquakes occurred from January 1977 to December 2004. The trend at the top reports the $k$ (the logarithm of energy in joule) values of the earthquakes located in a circle of a radius of $350 \mathrm{~km}$ around the centre of the hydro-geochemical network indicated in the Fig. 1. The middle trend shows the values of the $k_{s}$ index and the trend at the bottom the values of the $\varepsilon$ index.

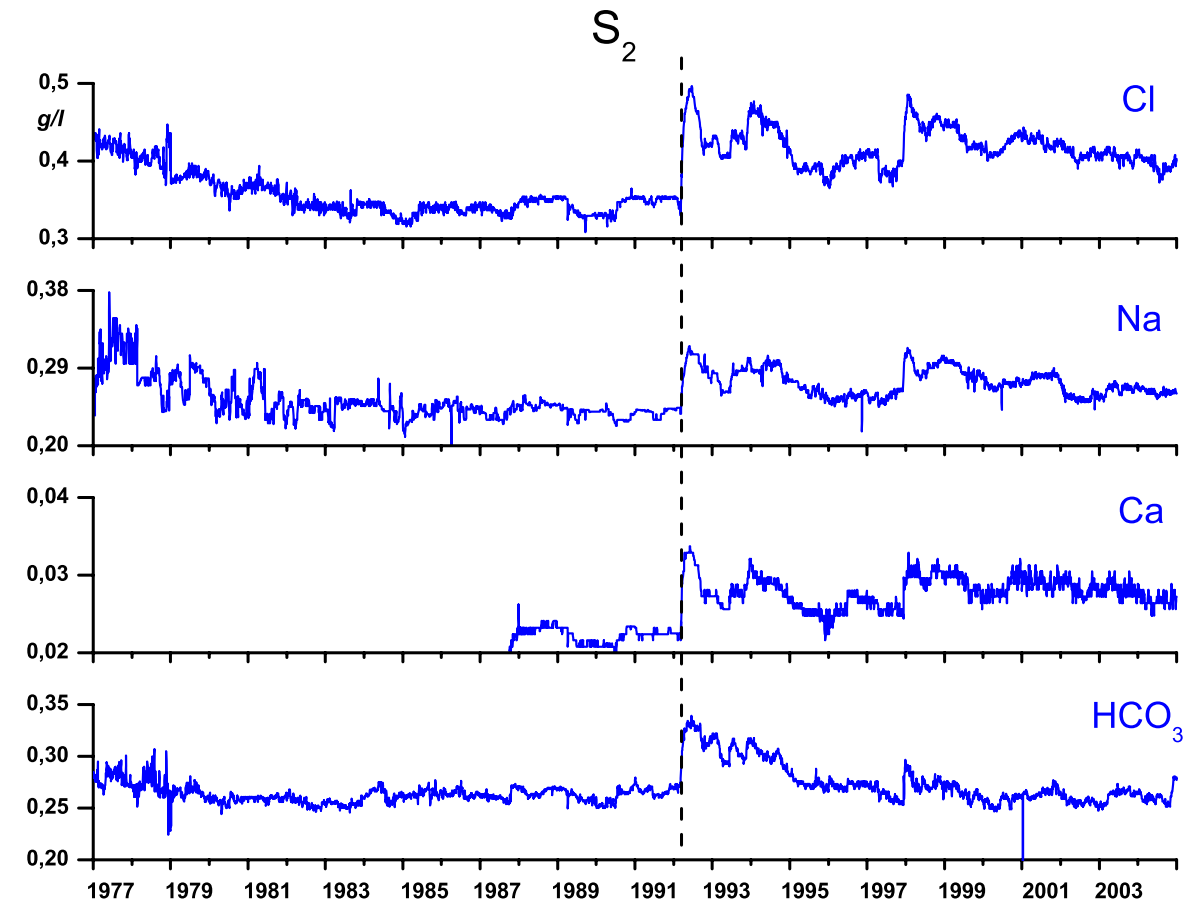

Fig. 3. From the top to the bottom: $\mathrm{Cl}, \mathrm{Na}, \mathrm{Ca}, \mathrm{HCO}_{3}$ ions content in the water of the spring $\mathrm{S}_{2}$ from $1977 / 1987$ to 2004 . The vertical line indicates the occurrence of the 2 March 1992 earthquake.

Post-seismic effects can be recognized also in the spectral content of the geochemical data pointed out in the Fig. 4.
First of all, it must be noted that the period of 6 days, revealed in the spectra of $\mathrm{N}_{2}$ and $\mathrm{Ar}$ content at $\mathrm{S}_{2}$ after the 


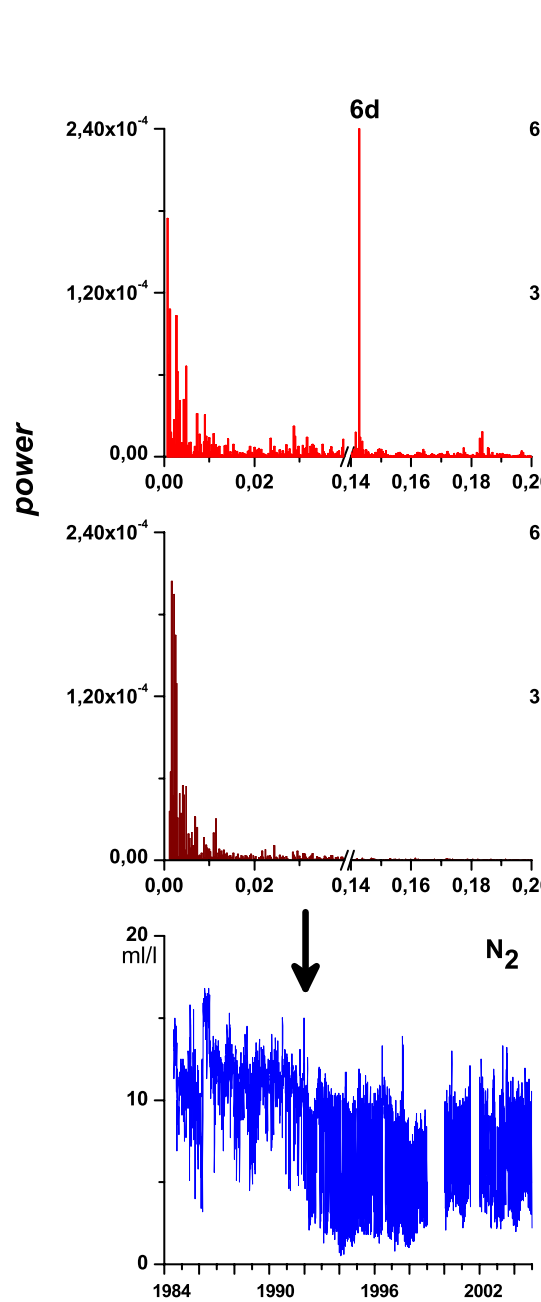

(a)<smiles>S=[SbH]</smiles>
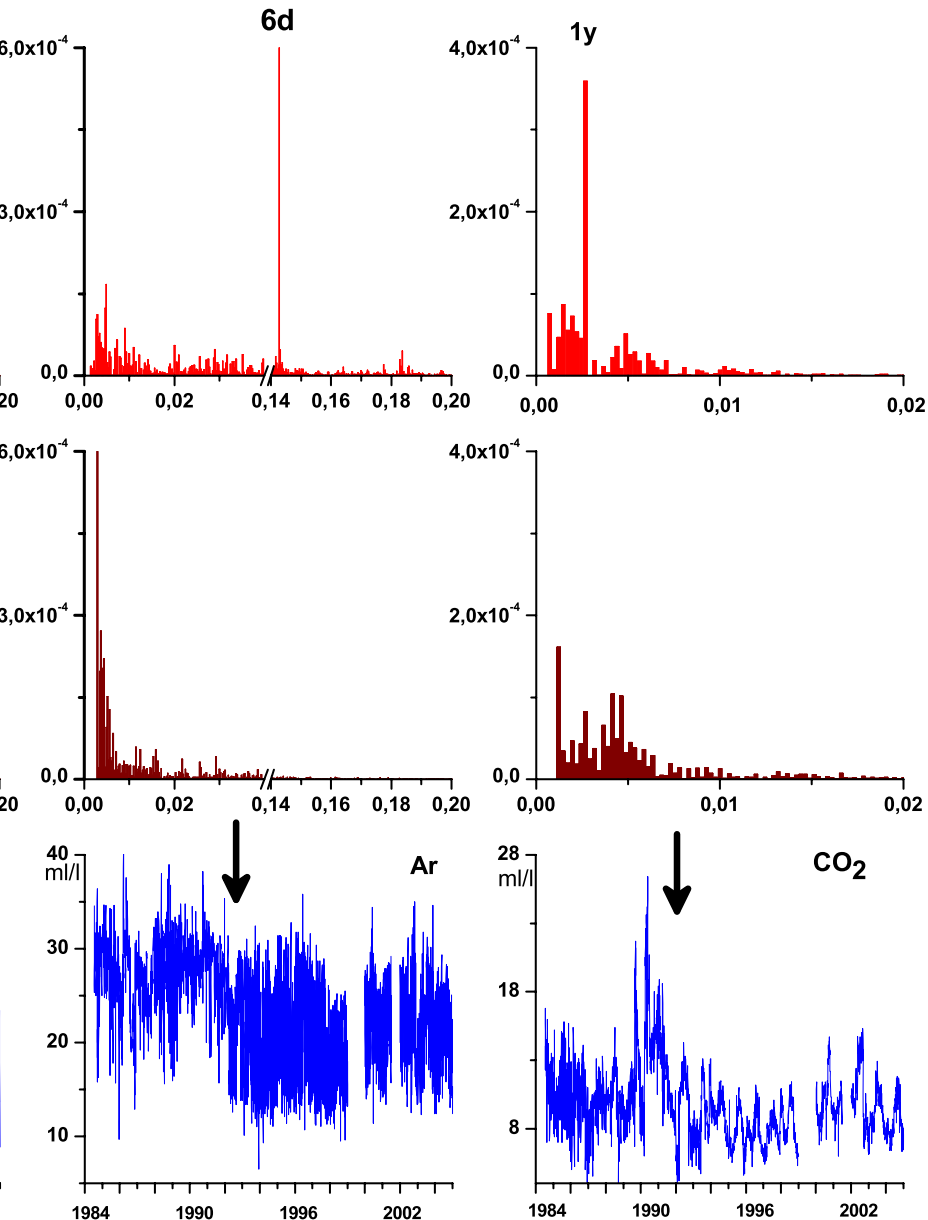

(b)

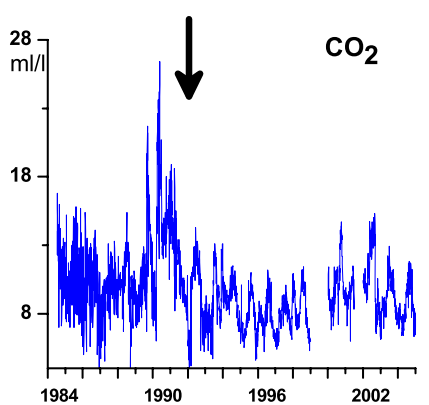

(c)

Fig. 4. (a) At the bottom the $\mathrm{N}_{2}$ content in the water of the spring $S_{2}$ from 1984 to 2004 . The middle and top graphs are the spectra of the $\mathrm{N}_{2}$ content data in the period 1984-1991 and 1992-2004, respectively. (b) At the bottom the Ar content in the water of the spring $\mathrm{S}_{2}$ from 1984 to 2004. The middle and top graphs are the spectra of the Ar content data in the period 1984-1991 and 1992-2004, respectively. (c) At the bottom the $\mathrm{CO}_{2}$ content in the water of the spring $\mathrm{S}_{1}$ from 1984 to 2004 . The middle and top graphs are the spectra of the $\mathrm{CO}_{2}$ content data in the period 1984-1991 and 1992-2004, respectively. The arrows indicate the occurrence of the 2 March 1992 earthquake.

earthquake occurrence, cannot be considered as a real period in the data sets. In fact, taking into account that the data are collected with a 3 days mean sampling rate, the frequency corresponding to the period of 6 days is the Nyquist critical frequency (Papoulis, 1962). According to the meaning of this frequency we can say that the strong 6 days component in the spectra of the Figs. $4 \mathrm{a}$ and $\mathrm{b}$ is only indicative of the appearance in the data sets of components with shorter periods. These short oscillations in the $\mathrm{N}_{2}$ and Ar content at $\mathrm{S}_{2}$ and the annual variation in the $\mathrm{CO}_{2}$ content (Fig. 4c) at $\mathrm{S}_{1}$, appearing after the earthquake occurrence, should be related to meteorological effects (King et al., 1981; King, 1986). It means that the fractures and the cracks produced by the March 1992 earthquake were able to modify these underground waters from isolated types to ones in contact with the atmosphere. It must be noted that the post-seismic effects have been revealed only at the springs, while no modifications seem to appear in the waters of the wells. This is due to a different peculiarity of waters in the springs and wells. The former are characterized by an underground deep circulation in the zone where the viscoelastic underground medium beneath the Koryaksky volcano is present (Biagi et al., 2003); the latter are connected with the relative aquifers that are located in different geological situations. So, the phenomenology we observed can be justified by assuming that the occurrence of the March 1992 earthquake produced consistent 


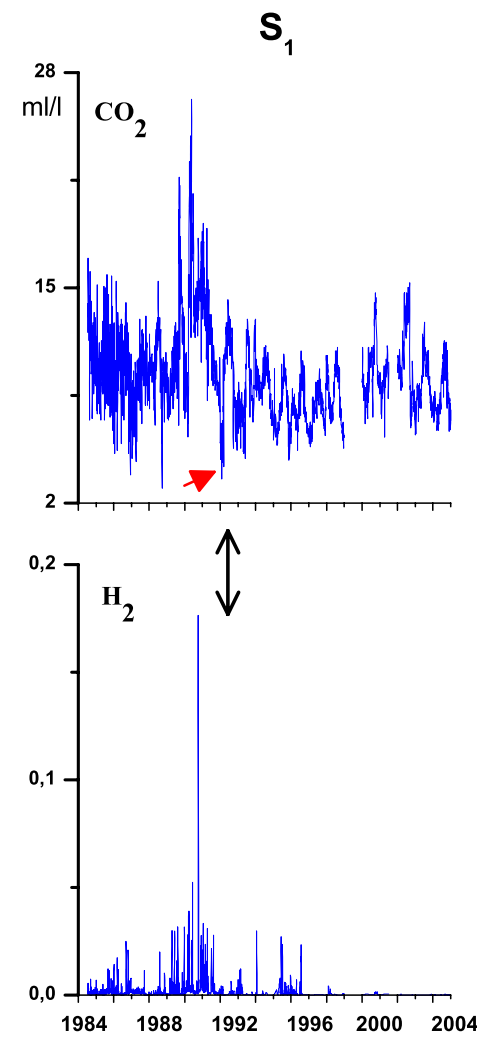

(a)
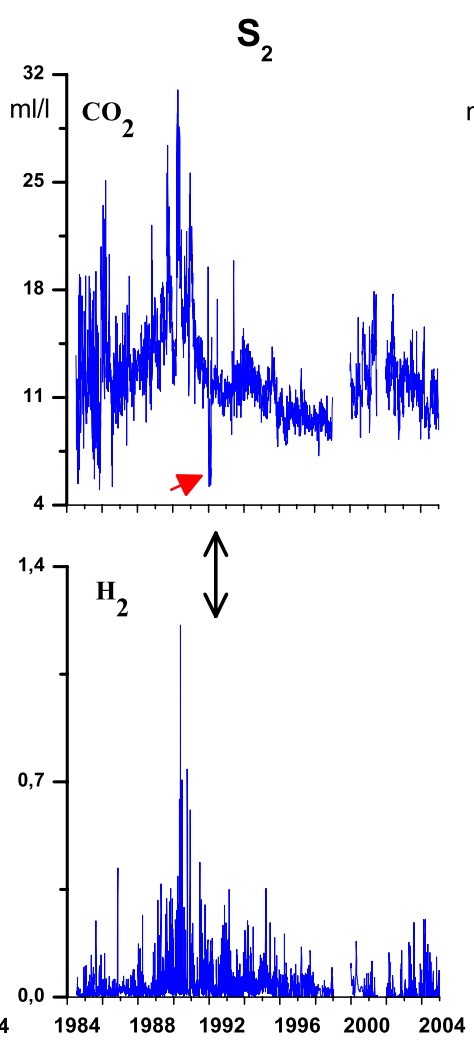

(b)

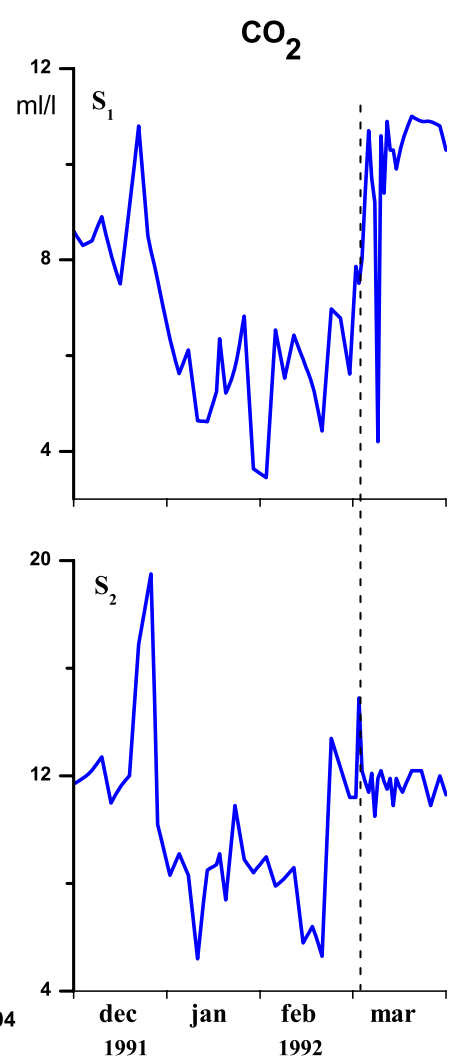

(c)

Fig. 5. (a) and (b) The $\mathrm{CO}_{2}$ and $\mathrm{H}_{2}$ contents in the water from 1984 to 2004 at the springs $\mathrm{S}_{1}$ and $\mathrm{S}_{2}$, respectively. The red arrows indicate the anomalous decreases enlarged in the Fig. 5c. The black double arrows mark the occurrence of the 2 March 1992 earthquake. (c) Zoom in the anomalous $\mathrm{CO}_{2}$ content decreases at the two spring from December 1991 to March 1992. The dashed line indicates the occurrence of the March 1992 earthquake.

modifications mainly in the volcanic underground structure. It must be noted that not only the post seismic effects of the March 1992 earthquake could be claimed to justify the previous modifications. In fact, some influence of all the strong seismic activity during the period 1992-1999 probably occurred.

The variations shown in the Figs. 5a, b, 6a and b can be assumed as long term precursors of the March 1992 earthquake. The most indicative parameter is the groundwater $\mathrm{CO}_{2}$ content because its variations are strictly connected with increases of stress. In fact, the $\mathrm{CO}_{2}$ reservoir is the ground, where the $\mathrm{CO}_{2}$ gas is formed by different processes, mainly biogenic ones (Mason and Moore, 1982; Fornaseri, 1994). An increase of stress produces an intensification of the micro-fracturing processes and/or changes in the existing fissures in the rocks surrounding the groundwater. As a consequence, the $\mathrm{CO}_{2}$ gas escapes from the ground along new or different directions increasing or reducing its contribution to the groundwater and a variation appears in the amount of the $\mathrm{CO}_{2}$ dissolved (Heinicke et al., 1995; Biagi et al., 2004b). So, the long term precursors in the $\mathrm{CO}_{2}$ content, observed at each measurement site, indicate that a stress increase happened in the area of the hydro-geochemical network during the two-four years preceding the March 1992 earthquake. The concomitant variation in the $\mathrm{H}_{2}$ content at each measurement site and the variation both in the $\mathrm{CH}_{4}$ content and in the water temperature at $\mathrm{W}_{2}$, must be interpreted as secondary variations related to the general and local underground structural situation of the zone. According to our opinion, the stress increase took place in a very large area of the southern Kamchatka and the earthquake happened in a zone where the breaking point was reached. It seems possible to connect the quoted stress variation not only with the March 1992 earthquake but with all the increase in the peak energy release from 1992 to 1999 pointed out previously. In such a case several conditions near to the breaking point were produced and the variations shown in the Figs. 5a, b, 6a and b were so important because they were related to a larger phenomenology than the occurrence of a single strong earthquake. 


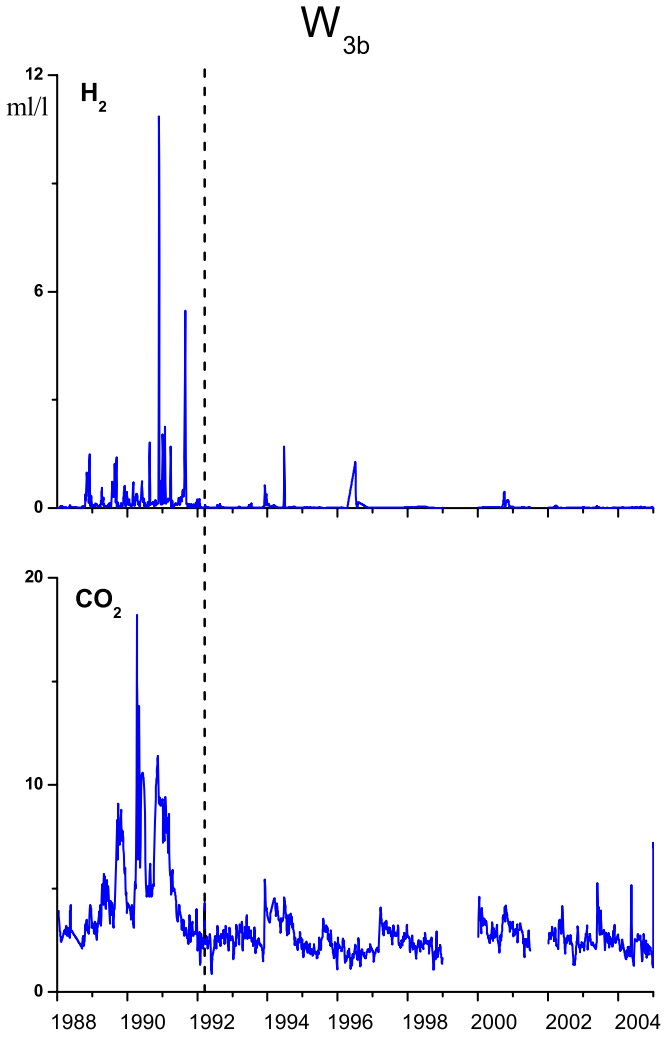

(a)

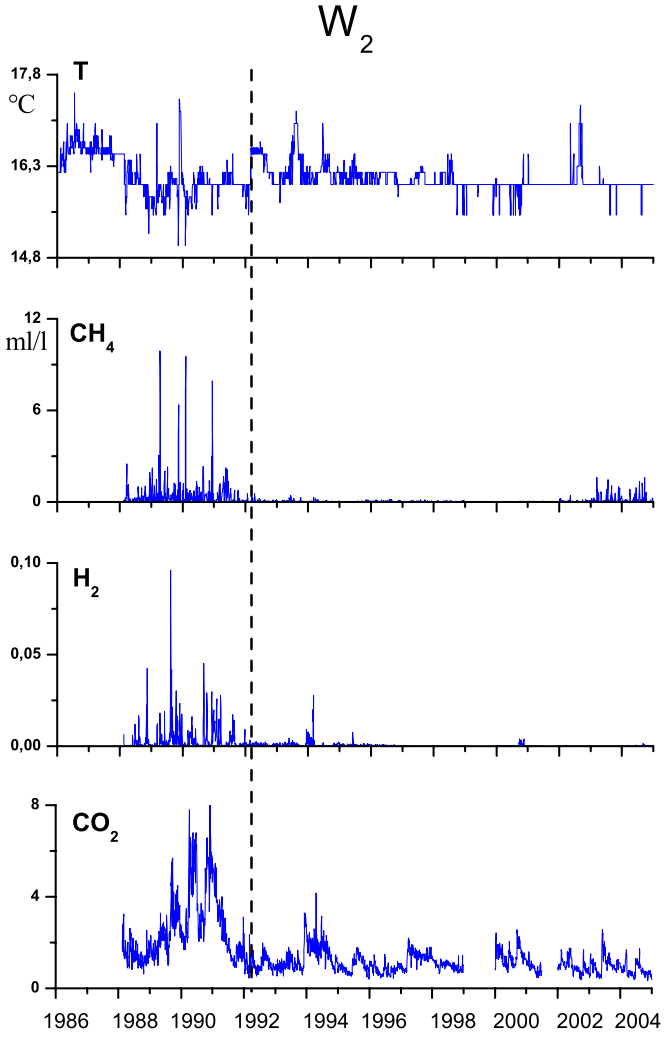

(b)

Fig. 6. (a) The $\mathrm{CO}_{2}$ and $\mathrm{H}_{2}$ content in the water of the well $\mathrm{W}_{3 b}$ from 1988 to 2004. (b) From the top to the bottom, the water temperature $T$ and the $\mathrm{CH}_{4}, \mathrm{H}_{2}, \mathrm{CO}_{2}$ content in the water of the well $\mathrm{W}_{2}$ from 1986/1988 to 2004. The vertical dashed lines indicate the occurrence of the 2 March 1992 earthquake.

The anomalous variations, with a duration of two-three months, revealed in the $\mathrm{CO}_{2}$ contents at $\mathrm{S}_{1}$ and $\mathrm{S}_{2}$ (Figs. 5a and b; enlarged in Fig. 5c) can be considered middle term precursors of the March 1992 earthquake. In a previous study (Biagi et al., 2000b), more evident precursors of this type were pointed out at $\mathrm{W}_{2}$ in the groundwater contents of some ions. It was proposed that some modification in the micro-fracturing processes or in the changes of the existing fissures, during the final stage of the preparatory phase of the earthquake, brought about the temporary mixing of different waters. By taking into account the previous explanation of the groundwater $\mathrm{CO}_{2}$ variations, the $\mathrm{CO}_{2}$ anomalies here we claimed can be justified by the same modification in the fracturing processes.

\section{Conclusions}

From this study, the following main statements can be claimed:

a) On the occasion of large ( $\mathrm{M}$ equal to 7.0 or more) earthquakes, post-seismic effects can be observed.

b) These effects do not appear at each measurement site of a hydro-geochemical network. It means that they are related to some local phenomenology connected with the underground structural situation.

c) Long term (some year) precursors seem to appear at each measurement site of a hydro-geochemical network. Probably, these variations are connected with large increases of stress and, as precursors, they could be related to more than one strong earthquake.

Edited by: M. Contadakis

Reviewed by: A Kies 


\section{References}

Bella, F., Biagi, P. F., Caputo, M., Cozzi, E., Della Monica, G., Ermini, A., Gordeev, E.I., Khatkevich, Y. M., Martinelli, G., Plastino, W., Scandone, R., Sgrigna, V., and Zilpimiani, D.: Hydrogeochemical anomalies in Kamchatka (Russia), Phys. Chem. Earth, 23, 921-926, 1998.

Biagi, P. F., Bella, F., Cozzi, E., Ermini, A., Scandone, R., Khatkevich, Y. M., Gordeev, E. I., Kingsley, S. P., Anderson, C. W., and Derlien, P. J.: Groundwater Argon content on the occasion of strong earthquakes in a seismogenetic area of Kamchatka (Russia), Il Nuovo Cimento C, 22, 503-508, 1999.

Biagi, P. F., Bella, F., Ermini, A., Cozzi, E., Gordeev, E. I., and Khatkevich, Y. M.: Hydrogeochemical precursors in Kamchatka (Russia) related to the strongest earthquakes in 1988-1997, Natural Hazards ,21, 263-276, 2000a.

Biagi, P. F., Ermini, A., Kingsley, S. P., Khatkevich, Y. M., and Gordeev, E. I.: Groundwater ion content precursors of strong earthquakes in Kamchatka (Russia), Pure Appl. Geophys., 157, 302-320, 2000b.

Biagi, P. F., Piccolo, R., Ermini, A., Fujinawa, Y., Kingsley, S. P., Khatkevich, Y. M., and Gordeev, E. I.: Hydrogeochemical precursors of strong earthquakes in Kamchatka: further analysis, Nat. Hazards Earth Syst. Sci., 1, 9-14, 2001a.

Biagi, P. F., Ermini, A., Khatkevich, Y. M., and Gordeev, E. I.: Difficulties with interpreting changes in groundwater gas content as earthquake precursors in Kamchatka (Russia), J. Seismol., 5, 487-497, 2001b.

Biagi, P. F., Molchanov, O., Piccolo, R., Minafra, A., Ermini, A., Capozzi, V., Khatkevich, Y. M., and Gordeev, E. I.: Copostseismic hydrogeochemical anomalies in a volcanic environment, Nat. Hazards Earth Syst. Sci., 3, 263-267, 2003, http://www.nat-hazards-earth-syst-sci.net/3/263/2003/.

Biagi, P. F., Piccolo, R., Minafra, A., Maggipinto, T., Castellana, L., Molchanov, O., Ermini, A., Capozzi, V., Perna, G., Khatkevich, Y. M., and Gordeev, E. I.: Retrospective analysis for detecting seismic precursors in groundwater argon content, Nat. Hazards Earth Syst. Sci., 4, 9-15, 2004a.
Biagi, P. F., Castellana, L., Piccolo, R., Minafra, A., Maggipinto, G., Ermini, A., Capozzi, V., Perna, G., Khatkevich, Y. M., and Gordeev, E. I.: Disturbances in groundwater chemical parameters related to seismic and volcanic activity in Kamchatka (Russia), Nat. Hazards Earth Syst. Sci., 4, 535-539, 2004b.

Dobrovolsky, I. P., Zubkov, S. I., and Miachkin, V. I.: Estimation of the size of earthquake preparation zone, Pure Appl. Geophys., 117, 1025-1044, 1979.

Fedotov, S. A., Gusev, A. A., Shumilina, L. S., and Chernyshova, V. G.: The seismofocal zone of Kamchatka, (in Russian), Volc. and Seismol., 4, 91-107, 1985.

Fornaseri, M.: Lezioni di geochimica, Masson S.p.A., Milano, 824 pp., 1994.

Heinicke, J., Koch, U., and Martinelli, G.: $\mathrm{CO}_{2}$ and Radon measurements in the Vogtland area (Germany) - a contribution to earthquake prediction research, Geophys. Res. Lett., 22, 771774, 1995.

King, C. Y., Evans, W. C., Presser, T., and Husk, R. H.: Anomalous chemical changes in well waters and possible relation to earthquakes, Geophys. Res. Lett., 8, 425-428, 1981.

King, C. Y.: Gas geochemistry applied to earthquake prediction: An overview, J. Geophys. Res., 91, 12 269-12 281, 1986.

Kingsley, S. P., Anderson, C. W., Biagi, P. F., Derlien, P. J., Ermini, A., Gordeev, E. I., and Khatkevich, Y. M.: Analysis of Argon concentration anomalies in underground water in Kamchatka (Russia), Il Nuovo Cimento C, 22, 407-413, 1999.

Kingsley S.P., P.F. Biagi, R. Piccolo, V. Capozzi, A. Ermini, Y.M. Khatkevich, and E.I. Gordeev, Hydrogeochemical precursors of strong earthquakes: a realistic possibility in Kamchatka, Phys. Chem. Earth, 26, 769-774, 2001.

Papoulis, A.: The Fourier integral and its applications, McGrawHill Book Company, 320 pp., 1962.

Mason, B. and Moore, C. B.: Principles of Geochemistry, John Wiley, New York, 344 pp., 1982.

Molchanov, O., Schekotov, A., Fedorov, E., Belyaev, G., and Gordeev, E.: Preseismic ULF electromagnetic effect from observation at Kamchatka, Nat. Hazards Earth Syst. Sci., 3, 1-7, 2003, http://www.nat-hazards-earth-syst-sci.net/3/1/2003/. 